\title{
Richard Trachsler (dir.), Moult obscures paroles. Études sur la prophétie médiévale
}

\section{Barbara Ferrari}

\section{(2) OpenEdition}

1 Journals

\section{Edizione digitale}

URL: http://journals.openedition.org/studifrancesi/7815

DOI: $10.4000 /$ studifrancesi.7815

ISSN: 2421-5856

\section{Editore}

Rosenberg \& Sellier

\section{Edizione cartacea}

Data di pubblicazione: 1 juillet 2009

Paginazione: 367-368

ISSN: 0039-2944

\section{Notizia bibliografica digitale}

Barbara Ferrari, «Richard Trachsler (dir.), Moult obscures paroles. Études sur la prophétie médiévale», Studi Francesi [Online], 158 (LIII | II) | 2009, online dal 30 novembre 2015, consultato il 09 janvier 2021 URL: http://journals.openedition.org/studifrancesi/7815 ; DOI: https://doi.org/10.4000/studifrancesi. 7815

Questo documento è stato generato automaticamente il 9 janvier 2021.

\section{(c) (†)}

Studi Francesi è distribuita con Licenza Creative Commons Attribuzione - Non commerciale - Non opere derivate 4.0 Internazionale. 


\title{
Richard Trachsler (dir.), Moult obscures paroles. Études sur la prophétie médiévale
}

\author{
Barbara Ferrari
}

\section{NOTIZIA}

RICHARD TRACHSLER (dir.), avec la collaboration de Julien ABED et David EXPERT, Moult obscures paroles. Études sur la prophétie médiévale, Paris, PUPS, 2007, pp. 271.

1 Questo volume costituisce senz'altro un valido punto di partenza per chi desideri avvicinarsi al ricco insieme dei testi profetici e divinatori francesi medievali, ancora in gran parte da esplorare. Anche se posta a chiusura del volume, va menzionata in primo luogo la preziosa bibliografia tematica di più di 600 titoli (pp. 219-259), utilissimo strumento di lavoro, all'interno della quale si segnala per completezza soprattutto la sezione merliniana.

2 All'intervento introduttivo del curatore Richard TRACHSLER ('Moult oscure parleüre'. Quelques observations sur la prophétie médiévale, pp. 7-14), che si sofferma sulla specificità del discorso profetico e sul ruolo che profezia e divinazione rivestirono nella società medievale, fanno seguito otto contributi divisi in due sezioni: «Devins et prophètes. Des pratiques similaires?» (pp. 15-78) e «Pour comprendre Merlin» (pp. 79-217).

3 Apre la prima il saggio di Doris RUHE (La Divination au Moyen Âge. Théories et pratiques, pp. 17-28), che ricorda come l'astrologia, inserita nel sistema delle sette arti liberali già nel De Nuptiis di Marziano Capella, venga studiata su nuove basi a partire dal XIII secolo grazie alla ricezione del sapere greco e arabo mediato da opere latine quali lo Speculum astronomiae. Descrizione scientifica al servizio di una migliore organizzazione della vita, essa diventa uno strumento prezioso per i laici detentori del potere che possono servirsene grazie alla mediazione dell'astrologo di corte. Testi come il Livre de Sidrac 
(metà del xiII s.) diffondono le tecniche della divinazione presso un pubblico più vasto grazie all'impiego del volgare.

4 Tony HUNT (Les pronostics en anglo-normand: méthodes et documents, pp. 29-50) presenta una ricca serie di testi divinatori in gran parte inediti. Dopo averne precisato i tratti distintivi, tanto sul piano formale che funzionale, lo studioso propone una ripartizione in cinque categorie principali: pronostici legati al calendario, astrologici, sortes (per es. serie di sentenze da consultare tirando a sorte), pronostici derivati da sistemi di calcolo concepiti per predire la buona ventura, tecniche diverse di divinazione (geomanzia, chiromanzia, onicomanzia o divinazione attraverso le unghie, ecc.).

5 Alessandro VITALE BROVARONE (Quand le prophète a raison. Une longue tradition, pp. 51-63) individua una categoria di testi, spesso burleschi, che manifestano diffidenza o sarcasmo verso gli indovini e i loro pronostici. Si tratta di una tradizione non uniforme, che risale all'antichità e arriva fino ad oggi e che, come mostrano gli esempi riportati, interessa diverse aree linguistiche.

6 Ernstpeter RUHE (L'invention d'un prophète: "Le livre de Sydrac", pp. 65-78) si concentra invece su di un solo testo. L'analisi dei due prologhi del Sidrac o Livre de la Fontaine des toutes sciences, grande opera enciclopedica del XIII s. redatta sotto forma di dialogo, gli permette di svelare il raffinato gioco intertestuale che lega il trattato alla Prophetia Danielis, al Merlin di Robert de Boron e alle Prophécies de Merlin, e di mostrare come l'anonimo autore, pur negando a Sidrac l'appellativo di 'profeta', gliene attribuisca in realtà tutte le caratteristiche.

7 La seconda parte, dedicata interamente a Merlino, si apre con lo studio di Julien ABED, $L a$ traduction française de la "Prophetia Merlini" dans le "Didot-Perceval" (Paris, BnF, nouv. acq. fr. 4166) (pp. 81-105), che analizza questo caso di interpolazione, unico in ambito francese ma presente nelle versioni iberiche del ciclo di Robert de Boron, tanto dal punto di vista della tecnica traduttoria, quanto da quello letterario. Lo studioso riesamina inoltre, con interessanti osservazioni, il problema dei rapporti tra il testo latino, quello francese e le versioni spagnole.

8 L'ampio contributo di Géraldine VEYSSEYRE ('Mettre en roman' les prophéties de Merlin. Voies et détours de l'interprétation dans trois traductions de l'Historia regum Britannie", pp. 107-166) prende in esame le trasformazioni che le Prophetie Merlini subiscono nell'Estoire des Bretons, nella Chronique des Bretons (traduzioni anonime rispettivamente del XIII e della prima metà del xv s.) e nel Roman de Brut di Jehan Wauquelin (1444-1445). La difficoltà e l'oscurità del testo ne fanno "un observatoire privilégié du métier de chaque traducteur, du projet qui sous-tend son travail, des modalités de sa mise en œuvre" (p. 111). Il confronto tra le diverse traduzioni fornisce inoltre preziose informazioni sulle lezioni degli esemplari latini utilizzati dai volgarizzatori.

claire WILLE affronta Le dossier des commentaires latins des "Prophetie Merlini" (pp. 167-184), costituito da una ventina di testi redatti tra il xII e il XV s. La studiosa analizza in un primo tempo il rapporto tra i commenti e la struttura interna delle Prophetie, e si sofferma poi su una profezia in particolare, la sedicesima, mettendo a confronto le diverse esegesi che la riguardano.

10 Nathalie KOBLE (Un univers romanesque en expansion. Les "Prophecies de Merlin" en prose du Pseudo-Richard d'Irlande, pp. 185-217) riflette sulle Prophecies de Merlin in prosa, redatte in Italia verso il 1270 da un francescano spirituale di origine veneziana, testo di cui sta curando l'edizione critica. L'ampia indagine presentata mette in luce le particolarità del 
“croisement poétique" (p. 187) tra profezia e romanzo arturiano realizzato dall'autore medievale.

11 Oltre alla Bibliografia, già menzionata, il volume è completato da un dossier iconografico (tav. I-XII) e da due indici: il primo, selettivo, relativo agli autori, opere e nozioni (pp. 261-263), il secondo (pp. 264-267) comprendente la lista dei manoscritti citati . 